\title{
Photopolymerization of Methyl Methacrylate Initiated by Iodine-Monoethanolamine
}

\author{
Sumihiro SAKaI and Kazunobu TAKAhashi \\ Kanae Paint Co., Ltd., Joto-ku, Osaka, Japan. \\ Naokazu SAKota \\ Department of Industrial Chemistry, Faculty of Engineering, \\ Ehime University, Bunkyo-cho, Matsuyama, Japan.
}

(Received September 10, 1973)

\begin{abstract}
The photopolymerization of methyl methacrylate (MMA) in the presence of iodine $\left(\mathrm{I}_{2}\right)$ and monoethanolamine (MEA) was investigated and compared with that of MMA photosensitized by $\mathbf{I}_{2}$-triethylamine. The kinetic data suggested that the photopolymerization of MMA with $I_{2}-$ MEA proceeded by a radical mechanism. The composition curve of the photosensitized copolymerization of MMA and styrene with $\mathrm{I}_{2}-$ MEA also supported the radical mechanism.

The ultraviolet spectrum of $\mathbf{I}_{2}$ and MEA in dichloromethane solution showed a charge-transfer absorption band at $245 \mathrm{~nm}$, and the absorbance near the maximum wavelength measured by the continuous variation method suggested the formation of a charge-transfer complex with a $1: 1$ molar ratio of $\mathrm{I}_{2}$ and MEA.

It seems likely that monoethanolamine hydroiodide and $N$ - $\beta$-hydroxyethylidenemonoethanolamine hydroiodide are formed by decomposition of the charge-transfer complex, and that photolysis of the latter yields a radical of diethanolamine which initiates the polymerization of MMA. Monoethanolamine hydroiodide was also found to have a photosensitizing effect for the polymerization of MMA in an excess of monoethanolamine.
\end{abstract}

KEY WORDS Photopolymerization / Methyl Methacrylate / Iodine / Monoethanolamine / Radical Mechanism / Charge-Transfer Absorption / Charge-Transfer Complex / Monoethanolamine Hydroiodide / $N$ - $\beta$-Hydroxyethylidenemonoethanolamine /

The photopolymerization of methyl methacrylate (MMA) by iodine $\left(I_{2}\right)$ with amines and aryl iodide with amine were reported in previous papers. ${ }^{1,2}$ In MMA solution, $I_{2}$ and triethylamine (TEA) formed a charge-transfer complex which, in the presence of an excess of TEA, decomposed to triethylamine hydroiodide (TEA-HI) and $N, N$-diethyl- $\alpha$-iodoethylamine. On UV irradiation the latter compound decomposed to a radical of triethylamine, which would initiate the photopolymerization of MMA. ${ }^{1}$

Although the $\mathrm{I}_{2}$-monoethylamine system showed no photosensitizing effect, the $\mathrm{I}_{2}$-monoethanolamine (MEA) system could initiate the photopolymerization of MMA. In the present paper, the photopolymerization of MMA in the presence of $\mathrm{I}_{2}$-MEA was studied to elucidate the initiation mechanism in comparison with that by $\mathrm{I}_{2}-\mathrm{TEA}$; an ultraviolet spectroscopic investigation of the $\mathrm{I}_{2}$-MEA complex was also carried out.

\section{EXPERIMENTAL}

\section{Materials}

Commercial methyl methacrylate and styrene were purified by the usual procedures and distilled just before use for polymerization. Iodine was purified by sublimation several times and dried over calcium chloride. Monoethanolamine was dried over potassium hydroxide, and then distilled in a nitrogen stream under reduced pressure. The fraction distilled at $99-100^{\circ} \mathrm{C} /$ $48 \mathrm{mmHg}$ was used for the experiments. The 
solvents, such as methanol, benzene, and chloroform, were purified by the usual methods. Dichloromethane of the special reagent grade (Wako Chemicals) was used for the measurement of the ultraviolet spectrum without further purification.

\section{Procedure}

Given amounts of iodine in MMA solution and MEA in methanol solution were placed in a glass ampoule for polymerization. The glass ampoule was degassed three times by the freezethaw method and then was sealed. The photopolymerization was carried out in a sealed ampoule under shaking and rotating around a 300W high-pressure mercury lamp (PIH 300 made by Eiko Co.) at $35.0 \pm 0.1^{\circ} \mathrm{C}$. The polymerization was stopped by the addition of excess methanol, and the conversion was determined from the amount of the precipitated polymer after drying. The number-average polymerization degree of poly-MMA was calculated according to the following equation, ${ }^{3}$ using the intrinsic viscosity $[\eta]$ measured in benzene solution at $30^{\circ} \mathrm{C}$.

$$
\log \bar{P}_{n}=3.346+1.32 \log [\eta]
$$

A JASCO Model ORD/UV 5 Spectropolarimeter was used for evaluating the ultraviolet spectra of the $\mathrm{I}_{2}-$ MEA complex.

\section{RESULTS AND DISCUSSION}

The polymerization of MMA was photosensitized by $I_{2}$ in the presence of excess MEA, as shown in Figure 1, though it was inhibited by $I_{2}$ without MEA. In this figure, the polymerization was accelerated with the increase of $I_{2}$ concentration, though it was accompanied by an induction period in the presence of $\mathrm{I}_{2}$ of greater concentration than $2.5 \times 10^{-3} \mathrm{~mol} / l$.

The values of $-\mathrm{d}[\mathrm{M}] / \mathrm{d} t$ calculated from the results of Figure 1 are plotted against the reaction time in Figure 2. The initial rates of polymerizations, calculated by the extrapolation of $-\mathrm{d}[\mathrm{M}] / \mathrm{d} t$ to zero time in Figure 2, exhibit a linear relationship to the square root of the $I_{2}$ concentration, as shown in Figure 3. Above $2.5 \times 10^{-3} \mathrm{~mol} / l$ of $\mathrm{I}_{2}$, however, the linear relationship deviates gradually with the increase of $\mathrm{I}_{2}$ concentration.

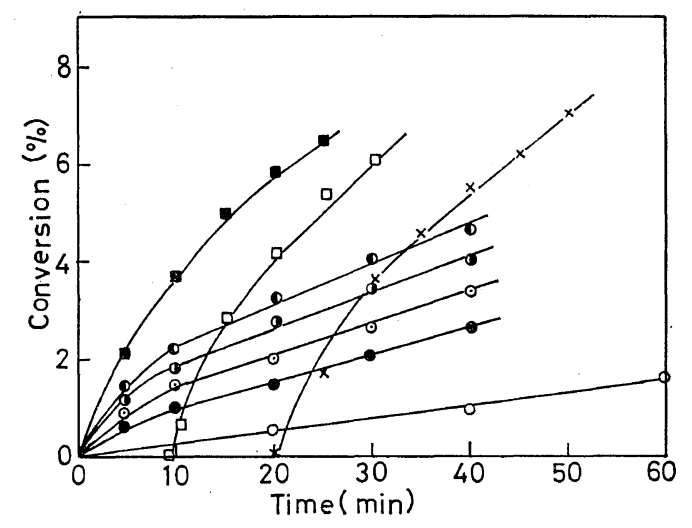

Figure 1. Conversion vs. time curves of the photopolymerization of MMA initiated by the $\mathrm{I}_{2}-\mathrm{MEA}$ system at $35^{\circ} \mathrm{C}: \mathrm{MMA}, 4 \mathrm{ml}$; $\mathrm{MeOH}, 1 \mathrm{ml}$; [MEA], $1.00 \mathrm{~mol} / l . \quad\left[\mathrm{I}_{2}\right], \mathrm{mol} / \mathrm{l}:-\mathrm{O}-, 0 ;-\bigcirc-1.98 \times$ $10^{-4}$; -○-, $3.96 \times 10^{-4} ;-\bigcirc-, 7.92 \times 10^{-4} ;-\mathbf{D}$, $1.58 \times 10^{-3} ;-\square-, 2.50 \times 10^{-3} ;-\square-, 4.99 \times 10^{-3}$; $-\times-, 1.04 \times 10^{-2}$.

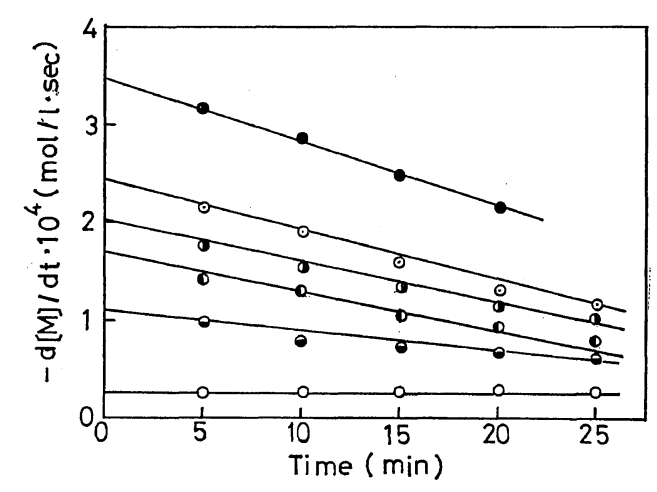

Figure 2. Relationship between $-\mathrm{d}[\mathrm{M}] / \mathrm{d} t$ and reaction time at $35^{\circ} \mathrm{C}: \mathrm{MMA}, 4 \mathrm{ml} ; \mathrm{MeOH}, 1 \mathrm{ml}$; [MEA], $1.00 \mathrm{~mol} / l . \quad\left[\mathrm{I}_{2}\right], \mathrm{mol} / \mathrm{l}:-\bigcirc-, 0 ;-\bigcirc-$, $1.98 \times 10^{-4} ;-\mathrm{D}-, 3.96 \times 10^{-4} ;-\bigcirc-, 7.92 \times 10^{-4}$; $-\odot-, 1.58 \times 10^{-3} ;-\bigcirc-, 2.50 \times 10^{-3}$.

The photopolymerization of MMA in the presence of $\mathrm{I}_{2}$-MEA, however, was inhibited by oxygen and was also retarded by hydroquinone. Furthermore, the photosensitized copolymerization of MMA and styrene by the $I_{2}-$ MEA system gave the radical composition curve shown in Figure 4. These facts suggest a radical mechanism for the photopolymerization in this system.

In the presence of a constant concentration of $\mathrm{I}_{2}\left(8.0 \times 10^{-3} \mathrm{~mol} / \mathrm{l}\right)$, MMA was photopoly- 
merized with varied concentrations of MEA (between 0.33 and $1.66 \mathrm{~mol} / \mathrm{l}$ ); the conversion is plotted against the polymerization time in Figure 5. Under these experimental conditions, the induction periods became gradually shorter with the increase of MEA concentration. At constant concentrations of $I_{2}$ and MEA, the photopolymerization was carried out in dichloroethane with varied concentrations of MMA, and the rates of polymerization were plotted against the monomer concentrations. The linear relation in Figure 6 exhibits a proportionality of $R_{\mathrm{p}}$ to

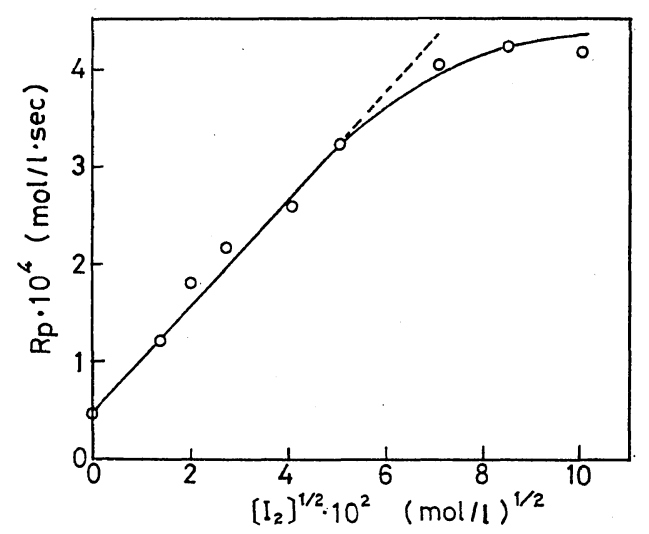

Figure 3. Relationship between $R_{\mathrm{p}}$ and $\left[\mathrm{I}_{2}\right]^{1 / 2}$ at $35^{\circ} \mathrm{C}$ : MMA, $4 \mathrm{ml}$; $\mathrm{MeOH}, 1 \mathrm{ml}$; [MEA], 1.00 $\mathrm{mol} / \mathrm{l}$. the monomer concentration.

The reciprocal of the number-average polymerization degree $\left(\bar{P}_{n}\right)$ of poly-MMA was plotted against $R_{\mathrm{p}}$ in Figure 7; a linear relationship was found at lower $R_{\mathrm{p}}$, while a rapid increase of $1 / \bar{P}_{n}$ occurred above the $R_{\mathrm{p}}$ value of $2.1 \mathrm{~mol} / \mathrm{l}-$ sec. The value of $\delta=k_{\mathrm{t}}^{1 / 2} / k_{\mathrm{p}}$ calculated from the slope of this straight line was 10.0 , which showed a good coincidence with the value ${ }^{4}$ obtained from the ordinary radical polymerization of MMA. The apparent overall activation energy of the photopolymerization calculated

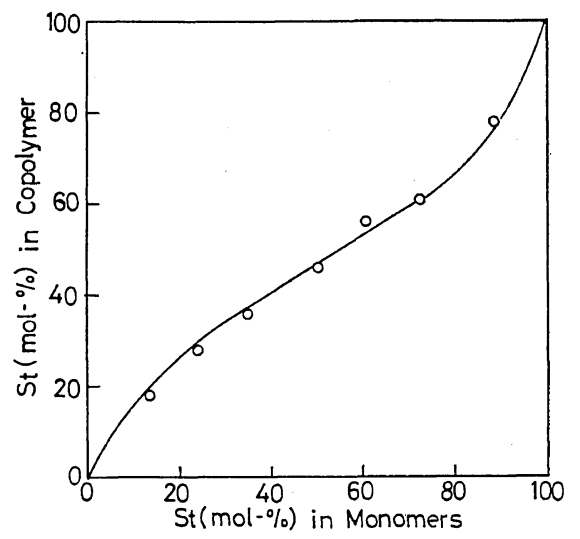

Fignre 4. Copolymerization of MMA and styrene at $35^{\circ} \mathrm{C}: \mathrm{MMA}+\mathrm{St}, 4 \mathrm{ml} ; \mathrm{MeOH}, 1 \mathrm{ml} ;\left[\mathrm{I}_{2}\right], 8 \times$ $10^{-3} \mathrm{~mol} / l$; [MEA], $1.00 \mathrm{~mol} / l$.

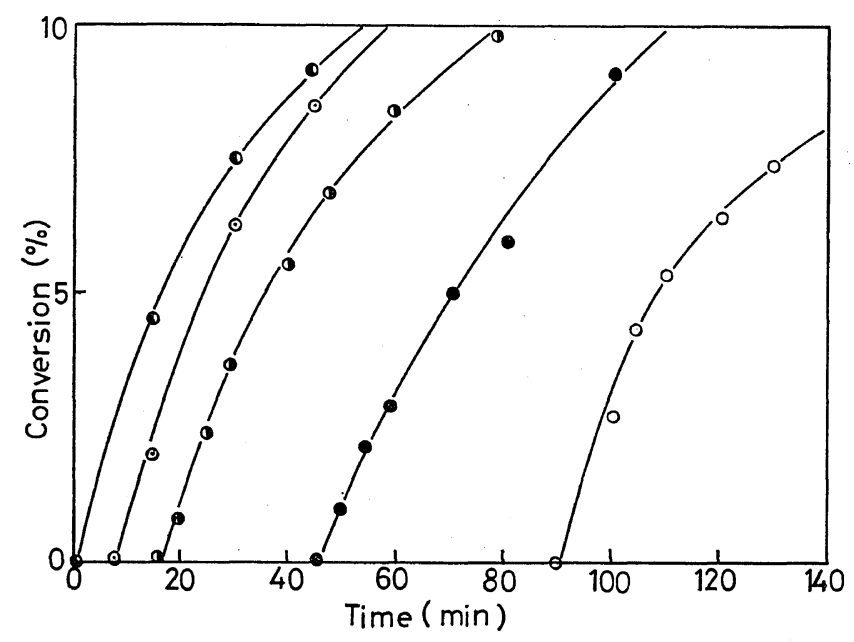

Figure 5. Conversion vs. time curves of the photopolymerization of MMA initiated by the $\mathrm{I}_{2}-\mathrm{MEA}$ system at $35^{\circ} \mathrm{C}$ : MMA, $4 \mathrm{ml} ; \mathrm{MeOH}, 1 \mathrm{ml} ;\left[\mathrm{I}_{2}\right]$, $8 \times 10^{-3} \mathrm{~mol} / \mathrm{l} ; \quad[\mathrm{MEA}], \mathrm{mol} / \mathrm{l}:-\bigcirc-, 1.66 ;-\bigcirc-, 1.00 ;-\bigcirc-, 0.83$; - -, $0.66 ;-\bigcirc-, 033$. 


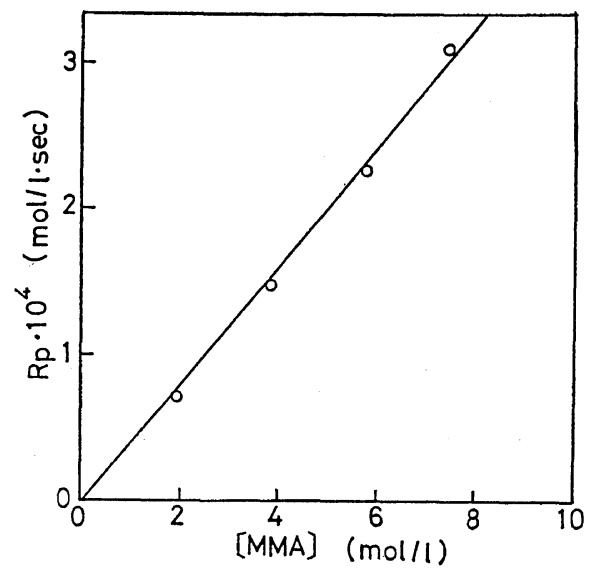

Figure 6. Relationship between $R_{\mathrm{p}}$ and MMA: MMA +dichloroethane, $4 \mathrm{ml} ; \mathrm{MeOH}, 1 \mathrm{ml} ;\left[\mathrm{I}_{2}\right]$, $8 \times 10^{-3} \mathrm{~mol} / l$; [MMA], $1.00 \mathrm{~mol} / l$.

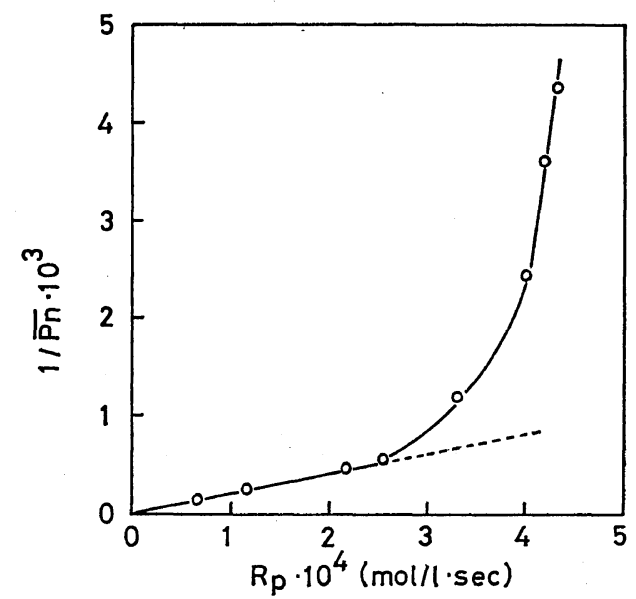

Figure 7. Relationship between $1 / \overline{\boldsymbol{F}}_{n}$ and $R_{\mathrm{p}}$ : MMA, $4 \mathrm{ml}$; MeOH, $1 \mathrm{ml}$; [MEA], $1.00 \mathrm{~mol} / l$.

from the correlation of $R_{\mathrm{p}} v s .1 / T$ in Figure 8 was $4.14 \mathrm{kcal} / \mathrm{mol}$, which showed a close agreement with that for the photosensitized polymerization of MMA by $2,2^{\prime}$-azobisisobutyronitrile (AIBN) or benzoyl peroxide (BPO). ${ }^{5}$

An iodine molecule in dichloromethane solution has no absorption maximum except $500 \mathrm{~nm}$ over the spectrum region from $230 \mathrm{~nm}$ to 700 $\mathrm{nm}$, and MEA in dichloromethane has no absorption maximum in this wavelength region. Adding $\mathrm{I}_{2}$ to MEA in dichloromethane at $25^{\circ} \mathrm{C}$, however, showed a new absorption maximum at $245 \mathrm{~nm}$ and shifted the $500-\mathrm{nm}$ absorption

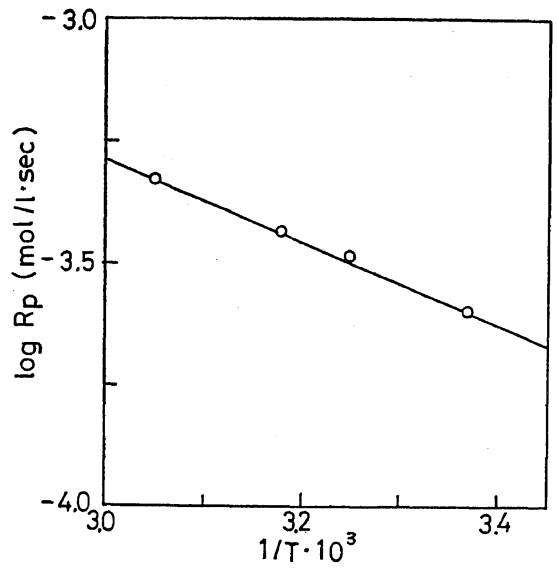

Figure 8. Arrhenius plot of $\log R_{\mathrm{p}}$ against $1 / T$ : MMA, $4 \mathrm{ml} ; \mathrm{MeOH}, \quad 1 \mathrm{ml} ; \quad\left[\mathrm{I}_{2}\right], 8 \times 10^{-3} \mathrm{~mol} / l$; [MEA], $1.00 \mathrm{~mol} / l$.

maximum of $I_{2}$ to $380 \mathrm{~nm}$. The charge-transfer absorption maxima of $\mathrm{I}_{2}$ with various amines have already been studied by many workers. ${ }^{6,7}$ For example, the formation of a charge-transfer complex of $\mathrm{I}_{2}$-ethylamine in $n$-heptane gave a charge-transfer absorption band at $246 \mathrm{~nm}$ and a shifted absorption maximum of $I_{2}$ at $417 \mathrm{~nm}$. Therefore, the $245-\mathrm{nm}$ absorption maximum of $I_{2}$ - MEA system could be ascribed to the chargetransfer complex formation. Keeping the total concentration of $I_{2}$ and MEA constant at $4 \times 10^{-4} \mathrm{~mol} / l$, the absorbances of the system at 245,260 , and $275 \mathrm{~nm}$ were determined by the continuous variation method. The correlation between the absorbances at the three wavelengths and the molar ratio of $I_{2}$ to MEA was determined at $25^{\circ} \mathrm{C}$ and is shown in Figure 9; the results indicate the formation of a 1:1 charge-transfer complex between $I_{2}$ and MEA. According to the method of Benesi-Hildebrand, ${ }^{8}$ the equilibrium constant $(K)$ of $\mathrm{I}_{2}$-MEA complex formation was calculated as 1330,1080 , and 830 at $15^{\circ} \mathrm{C}, 20^{\circ} \mathrm{C}$, and $25^{\circ} \mathrm{C}$, respectively. The heat of formation for the $\mathrm{I}_{2}$-MEA complex was calculated as $-8.6 \mathrm{kcal} / \mathrm{mol}$ from the linear relationship between the values of $\ln K$ and the reciprocals of the absolute temperatures. This value is somewhat closer to the value of the heat of formation for the $\mathrm{I}_{2}$-ethylamine complex $(-7.4 \mathrm{kcal} / \mathrm{mol})^{7}$ than that of the $\mathrm{I}_{2}-$ ethanol complex $(-2.1 \mathrm{kcal} / \mathrm{mol}) .{ }^{9} \quad$ This fact sug- 


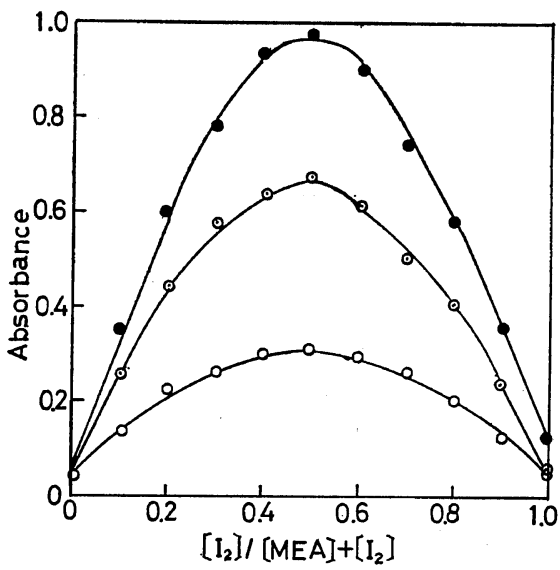

Figure 9. Relationship between the absorbance and the molar ratio of $\mathrm{I}_{2}-\mathrm{MEA}$ in dichloromethane at $25^{\circ} \mathrm{C}:\left[\mathrm{I}_{2}\right]+[\mathrm{MEA}], 4 \times 10^{-4} \mathrm{~mol} / l$; cell length, $10 \mathrm{~mm}$.

gests that the amino group of MEA would take a more important part in the formation of $\mathrm{I}_{2}-$ MEA complex than the hydroxyl group did.

The dichloromethane solutions of $I_{2}$ and MEA were prepared below $25^{\circ} \mathrm{C}$ and were poured into a $10-\mathrm{mm}$ quartz cell. It was then degassed by the freeze-thaw method and sealed. During the preparation, the mixed solution was carefully kept below $25^{\circ} \mathrm{C}$. After UV irradiation at $35^{\circ} \mathrm{C}$ for a definite time, the UV spectrum of the solution was determined while it was still in the sealed cell. Because of the irradiation, the absorbance of the 245-nm charge-transfer absorption band decreased rapidly to a lower constant value. At the same time, there appeared two more weak absorption maxima at 290 and $360 \mathrm{~nm}$, both of which presumably were ascribed to $\mathrm{I}_{3}{ }^{-}$. They became larger as the UV irradiation continued and attained constant values after several minutes. For the blank test, another sealed cell which contained $\mathrm{I}_{2}$ and MEA in dichloromethane was kept at $35^{\circ} \mathrm{C}$ without irradiation and the spectrum of the solution was also measured whlie it was still in the sealed cell. The same spectral change as in the case of the irradiation was observed, but the rate of disappearance of $245-\mathrm{nm}$ peak was somewhat slower than that by the irradiation. These results showed that the $\mathrm{I}_{2}$-MEA complex in dichloromethane would thermally decompose without irradiation.

Therefore, the authors studied the thermal effect on the $I_{2}-$ MEA complex in dichloromethane by another set of experiments, performed in darkness. Each dichloromethane solution of $\mathrm{I}_{2}$ and MEA was kept at a definite temperature $\left(25,30\right.$ or $\left.35^{\circ} \mathrm{C}\right)$ and mixed in a quartz cell with a glass cap; the UV spectrum was determined immediately after the mixing and after $0.5,1$, and $2 \mathrm{hr}$, at that temperature. No spectral change occurred when the solution stood for $2 \mathrm{hr}$ below $30^{\circ} \mathrm{C}$. At $35^{\circ} \mathrm{C}$, however, the 245-nm charge-transfer absorption band of the solution became smaller with increasing time. Moreover, the spectrum at $35^{\circ} \mathrm{C}$ exhibited two additional weak absorption maxima at 290 and $360 \mathrm{~nm}$ (Figure 10). Standing at $35^{\circ} \mathrm{C}$, the absorbances at $290 \mathrm{~nm}$ and $360 \mathrm{~nm}$ became larger with increasing time and the $245-\mathrm{nm}$ absorbance diminished.

These facts indicate that the $\mathrm{I}_{2}$-MEA complex rapidly decomposed above $35^{\circ} \mathrm{C}$ thermally as well as photochemically.

When $I_{2}$ was added to the dichloromethane solution of MEA above $35^{\circ} \mathrm{C}$, the red-brown color of $\mathrm{I}_{2}$ rapidly disappeared with a slightly exothermic reaction. Then the solution separated into two layers. The faintly coloured layer, which was not miscible with dichloromethane, gave a red-brown syrup after vacuum concentration. After standing at room temperature, a very hygroscopic crystalline material precipitated from the red-brown syrup. The raw crystalline material melted at $74-80^{\circ} \mathrm{C}$ and its ionic iodine content was $67.90 \%$. These results suggest that the crystalline material was monoethanolamine hydroiodide (MEA-HI), but an elemental analysis was impossible due to its hygroscopic nature. Although addition compounds of the MEA-I $\mathrm{I}_{2}$ and $(\mathrm{MEA})_{2}-\mathrm{I}_{2}$ types were reported to be produced in the reaction of MEA and $\mathrm{I}_{2}{ }^{10}$ the infrared data of the crystal convinced as that the reaction between them gave ultimately MEA-HI through the addition compound.

After removal of the crystalline material, the residual red-brown syrup showed an infrared absorption band of $\nu_{\mathrm{C}=\mathrm{N}}$ at $1695 \mathrm{~cm}^{-1}$, and it contained $54.03 \%$ of ionic iodine, which almost 


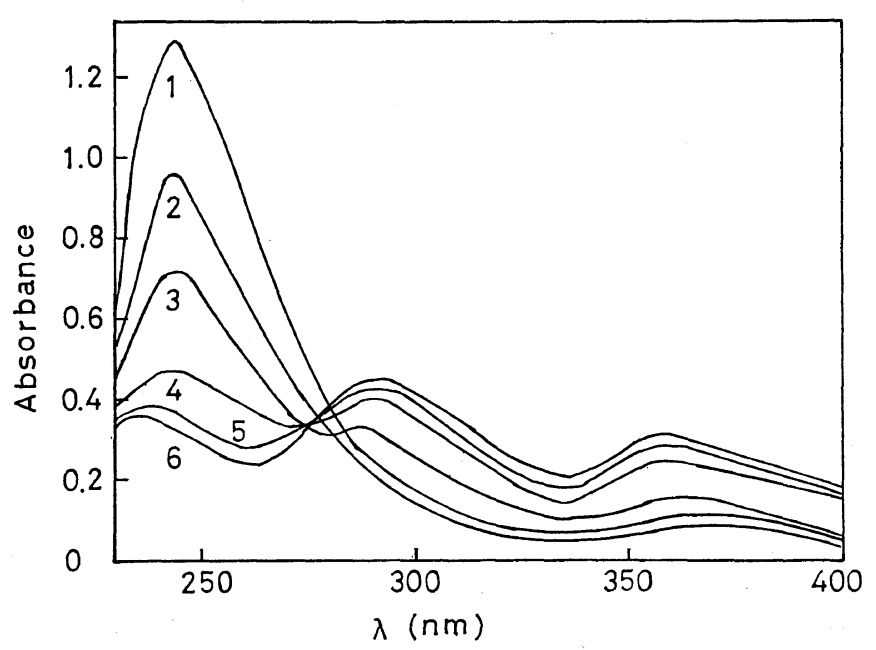

Figure 10. Ultraviolet spectra of the $I_{2}-$ MEA system in dichloromethane: $\left[\mathrm{I}_{2}\right], 4 \times 10^{-5} \mathrm{~mol} / l$; [MEA], $2 \times 10^{-3} \mathrm{~mol} / l$; cell length, $10 \mathrm{~mm}: 1$, immediately after mixing at $25^{\circ} \mathrm{C} ; 2$, immediately after mixing at $30^{\circ} \mathrm{C}$; 3 , immediately after mixing at $35^{\circ} \mathrm{C} ; 4$, after 30 -min standing at $35^{\circ} \mathrm{C}$ in darkness; 5, after 1 -hr standing at $35^{\circ} \mathrm{C}$ in darkness; 6, after 2-hr standing at $35^{\circ} \mathrm{C}$ in darkness.

corresponds to a ratio of one ionic iodine atom per two MEA molecules. The residual syrup was easily miscible with water and alcohols but immiscible with ether, benzene, etc., and gave 2,4-dinitrophenylhydrazone after reaction with 2,4-dinitrophenylhydrazine. The photoreduction of benzophenone by the primary and secondary alkyl amines gave the imino compound in high yields. ${ }^{11}$ The imines can be hydrolyzed to aldehydes and ketones, respectively, and will give 2,4-dinitrophenylhydrazone. Therefore, it is reasonable to consider that the red-brown residual syrup would be $N$ - $\beta$-hydroxyethylidenemonoethanolamine hydroiodide.

The photopolymerization of MMA was carried out in the presence of both the obtained crystalline material and the residual syrup; the results are shown in Figure 11. The conversion vs. time curves of these polymerization systems were compared with the sensitizing effects of the authentic MEA-HI and also with MEA. The photopolymerization of MMA could not be sensitized by MEA-HI at all. The presence of MEA-HI showed a rather lower conversion than that by MEA. The residual syrup, however, was able to intiate the photopolymerization without any induction period even in the absence

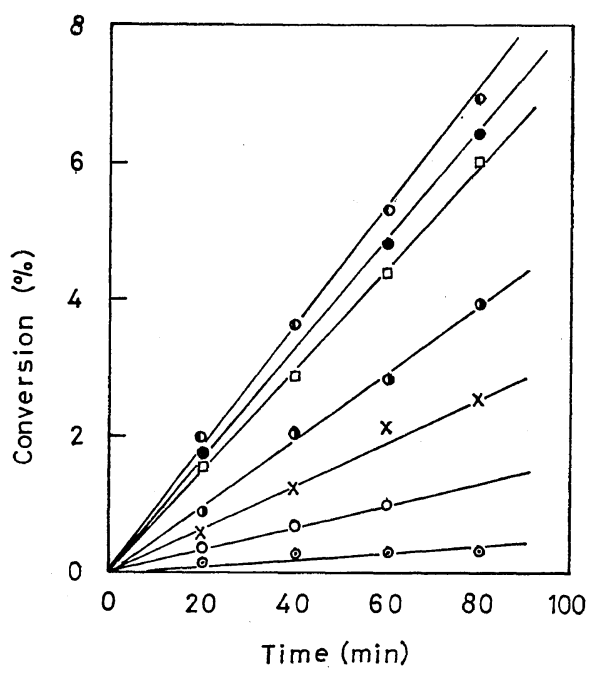

Figure 11. Photopolymerization of MMA by MEA-HI, residual syrup, and crystalline material at $35^{\circ} \mathrm{C}$ : MMA, $4 \mathrm{ml} ; \mathrm{MeOH}, 1 \mathrm{ml}:-\odot-$, MEA-HI, $10 \mathrm{mg}$; - - , residual syrup, $10 \mathrm{mg}$; - $\times$-, crystal, $10 \mathrm{mg}$; - -, MEA-HI, $10 \mathrm{mg}$, [MEA], $1.00 \mathrm{~mol} / l ;--$, syrup, $10 \mathrm{mg}$, [MEA], $1.00 \mathrm{~mol} / l ;-\square-$, crystal, $10 \mathrm{mg}$, [MEA], 1.00 $\mathrm{mol} / l ;$ - - , [MEA], $1.00 \mathrm{~mol} / l$.

of excess MEA. In the presence of the crystalline material, MMA could polymerize only slowly without MEA. By adding MEA to these 
polymerization systems, the rates of the polymerization of MMA became somewhat larger than those without MEA. Especially in the case of MEA-HI, which seems to inhibit the polymerization of MMA, the largest polymerization rate was obtained with an excess of MEA. The results suggest that the crystalline material is not a pure MEA-HI, but is contaminated with the residual syrup.

From these results, the following reaction schemes are suggested for the photopolymerization of MMA in the presence of MEA and $I_{2}$.

$$
\begin{aligned}
\mathrm{HOCH}_{2} \mathrm{CH}_{2} \mathrm{NH}_{2}+\mathrm{I}_{2} \rightleftharpoons\left[\mathrm{HOCH}_{2} \mathrm{CH}_{2} \mathrm{NH}_{2}-\mathrm{I}_{2}\right. \\
\left.\stackrel{\leftrightarrow}{\rightleftarrows} \mathrm{HOCH}_{2} \mathrm{CH}_{2} \stackrel{\oplus}{\mathrm{N}} \mathrm{H}_{2} \mathrm{I}-\stackrel{\ominus}{\mathrm{I}}\right] \\
\longrightarrow \mathrm{HOCH}_{2} \mathrm{CH}_{2} \mathrm{NHI}+\mathrm{HI}
\end{aligned}
$$

$\mathrm{HOCH}_{2} \mathrm{CH}_{2} \mathrm{NH}_{2}+\mathrm{HI} \rightleftharpoons \mathrm{HOCH}_{2} \mathrm{CH}_{2} \mathrm{NH}_{2} \cdot \mathrm{HI}$

$$
\begin{aligned}
& \text { (I) }+(\mathbf{I I}) \longrightarrow \mathrm{HOCH}_{2} \mathrm{CH}_{2} \mathrm{~N}=\mathrm{CHCH}_{2} \mathrm{OH} \cdot \mathrm{HI} \\
& +\mathrm{NH}_{4} \mathrm{I} \text { (III) } \\
& \text { (III) } \stackrel{h \nu}{\longrightarrow} \mathrm{HOCH}_{2} \mathrm{CH}_{2} \mathrm{NH}-\dot{\mathrm{C}} \mathrm{HCH} \mathrm{H}_{2} \mathrm{OH} \cdot \mathrm{HI}
\end{aligned}
$$

It seems likely that $N$-iodomonoethanolamine (I) will be formed at first by the dissociation of the charge-transfer complex of MEA and $\mathrm{I}_{2}$ (eq 1 ), and then the compound (I) will react with MEA-HI (II) which is formed from the excess MEA and HI (eq 2), and probably will be converted to $N$ - $\beta$-hydroxyethylidenemonoethanolamine hydroiodide (III) by the deamination (eq 3 ). During the irradiation of UV light, the compound (III) will yield the radical (IV) (eq 4) which is responsible for the initiation of the polymerization of MMA. Toshima, et al. ${ }^{12}$ reported that in the photoreduction of diphenylmethyleneimine in 2-propanol solution, the occurrence of an aminobenzhydryl radical from the photoactivated diphenylmethyleneimine was detected by ESR. Hence, it will be considered that the photoactivated $\mathrm{CH}=\mathrm{N}$ bond of the imine (III) transfers a hydrogen atom from the MEA or methanol used as the solvent to the radical (IV), which will be an initiating species.

It is interesting that MEA-HI can photosensitize the polymerization of MMA in the presence of an excess of MEA, though TEAHI could not initiate the polymerization so much even with an excess of TEA. Although the detailed process for the photopolymerization by MEA-HI with MEA is uncertain, it seems likely that by UV irradiation MEA-HI can release an iodine atom which will act as a radical scavenger and inhibit the polymerization of MMA. By adding MEA to this system, however, an iodine atom occurring from MEA-HI would transfer a hydrogen atom from MEA resulting in an initiating species.

Yokota, et al. ${ }^{13}$ reported on the photopolymerization of MMA by TEA; they deduced that a complex between the photoexcited monomer and TEA was produced, and then was decomposed into an initiating radical. An iodine formed by photolysis of TEA-HI and MEA-HI presumably acts as a radical scavenger and inhibits the polymerization. The photopolymerization in TEA-HI and MEA-HI systems, therefore, would have a lower rate of polymerization than TEA and MEA.

A detailed chemical investigation of the reaction between MEA and $I_{2}$ will be discussed in a later paper.

\section{REFERENCES}

1. N. Sakota, T. Nagasaki, and S. Sakai, Polymer J., 2, 192 (1971).

2. S. Sakai, T. Nagasaki, and N. Sakota, ibid., 3, 44 (1972).

3. F. J. Welch, J. Polym. Sci., 61, 243 (1962).

4. M. S. Matheson, E. E. Auer, E. B. Bevilacque, and E. J. Hart, J. Amer. Chem. Soc., 73, 5395 (1951).

5. Kh. S. Bagdasaryan, Zh. Fiz. Khim., 21, 25 (1947).

6. S. Nagakura, J. Amer. Chem. Soc., 80, 520 (1958).

7. H. Yada, J. Tanaka, and S. Nagakura, Bull. Chem. Soc. Japan, 33, 1660 (1960).

8. H. A. Benesi and J. H. Hildebrand, J. Amer. Chem. Soc., 71, 2703 (1949).

9. P. A. D. deMains, J. Chem. Phys., 26, 1192 (1957).

10. E. Jozefowicz and C. Wyganowski, Rocz. Chem., 46, 1953 (1972); Chem. Abstr., 78, 123912s (1973).

11. S. G. Cohen and R. J. Baumgarten, J. Amer. Chem. Soc., 89, 3471 (1967).

12. N. Toshima, H. Hirai, and S. Makishima, Kogyo Kagaku Zasshi (J. Chem. Soc. Japan, Ind. Chem. Sect.), 72, 184 (1969).

13. K. Yokota, H. Tomioka, T. Ono, and F. Kuno, J. Polym. Sci., Part A-1, 10, 1335 (1972). 